Neste trabalho o autor aborda suas observaçóes clínicas, mostrando que, em relação a tudo o que se considera aprendizagem e seus transtornos, a atitude de um psicanalista é diferente: antes de entregarse a discorrer sobre 0 tema, começa pelo exame de seus próprios transtornos de aprendizagem. Contudo, o psicanalista nāo se apropria da palavra "aprender" com a mesma determinação com que se incumbiu de vocábulos como "sexualidade" ou "desejo"; mantém certa inibição, uma inibição que é em si mesma um "transtorno de aprendizagem", como se não se sentisse cm sua casa e de pleno direito no que diz respeito a essa palayra. Não há atualmente algo equivalente a uma teoria psicanalítica da aprendizagen e seus destinos, e é nessse ponto que o autor arrisca uma interpretação.

Psicanalista; aprender; inibiçäo; transtorno de aprendizagem

\section{PERCEPTIONS FROM THE} CONSULTATION ROOM: THE PSYCHOANALYST AND HIS/HER OWN EXPERIENCE OF LEARNING

In this article the author approaches his slinic observations, showing that, relating to everything considered apprenticeship and its troubles, the attitude taken by a psychoanalyst is different: before beginning to discourse about the subject, examines his/her own troubles with learning. Nevertheless, the psychoanalyst doesn't appropriate the word "learning" with the same determination he/she exhibits when dealing with terms such as "sexuality" or "desire", he/she maintains a certain inhibition, which is in itself a "trouble of apprenticeship", as if he/ she didn't ieel at home and wasn't in his/her own right about this word. Presently there isn't anything like a psychoanalytical theory of learning and its ends. In this point the author risks an interpretation.

Psychoanalyst; learning; inhibition, trouble of apprenticeship

\section{PERCEPÇÕES DE CONSULTÓRIO: O PSICANALISTA E SUA PRÓPRIA EXPERIÊNCIA DE APRENDER ${ }^{1}$}

\author{
Ricardo Rodulfo
}

Tradução: Daniela Teperman

$\pi^{4}$ aprendizagem e seus transtornos, a atitude do psicanalista é diferente: antes de entregar-se a discorrer academicamente "sobre" o tema, começa pelo exame de seus próprios transtornos de aprendizagem ${ }^{2}$. E em mais de um plano: talvez não the interessará tanto "a pessoa", o analista como pessoa e suas eventuais inibições, mas o transtorno gerado no nível do texto e do dispositivo analítico, o transtorno na teoria ou no teorizar, o modo de esta funcionar gerando seu próprio transtorno, suas próprias resistências, nela mesma e na "mente" do analista que a usa.

Ainda com suas resistências dirigidas a si mesmo, andando ao passo lento de suas inércias e de suas limitações, é característica do trabalho do psica-

Psicanalista, professor da Universidade de Buenos Aires, doutor em Psicologia. Autor de "O brincar e o significante", editado no Brasil pela Editora Artes Médicas. 
nalista uma praxis de rebites tão singulares que, para começar, desacomoda e desacomoda-se da distinção - que é a de uma oposição rígida - entre "teoria" e "prática”. Quando o psicanalista traduz "em teoria” esta praxis que é a sua, costuma ocorrer um achatamento redutor para justificar-se como pertencente a tal escola ou a tal confraria. Mas essa pálida tradução não retroage - sempre que se trate de um psicanalista - sobre o que este faz. Afortunadamente, claro, excede o que ele diz que é. Pelo mesmo motivo, seu trabalho também não se reduz a uma técnica, ainda que contenha elementos técnicos ${ }^{3}$. Entre muitas outras conseqüências, esta singularidade traz consigo que o psicanalista, contra aquilo em que costuma acreditar, não pode "ter" uma teoria; não pode manter com ela uma relação que se possa verdadeiramente articular apelando aos verbos "ter" e "ser". O que, certamente, não implica que não tenha nenhuma relação com a teoria.

Em que medida a criança "tem" um objeto transicional? Ao ser uma "possessão não-eu", qualquer referência ao "ter" é imediatamente paradoxal. Não por causa do objeto, mas pelo estatuto que the confere a dimensão do transicional. Toscamente formulado: entre a teoria que o psicanalista leva ou guarda em sua cabeça, em seu "interior", e a prática que acredita exercer nesse fora, o "exterior", desdobra-se toda a espacialidade também paradoxal - por ser um "espaço potencial" (Winnicott, grifo meu) - do transicional, que é onde, na realidade, transcorre e se aloja a praxis do psicanalista. Por isso mesmo Freud não poderia ser "freudiano", nem Lacan "lacaniano": uma possessão não-eu não pode ser egossintônica, sustenta-se no intervalo de uma différance.

Quando alguém não conseguiu suportar as "impossibilidades", as imposições da posição do psicanalista (posição que também não se legitima por ser sintônica com uma determinada instituição, porque não há, de fato não é possível, uma instituição psicanalítica; há instituição "psicanalítica" e "instituição" psicanalítica, que é uma outra coisa), confunde facilmente essas relações de não-ter e de des-ser, com ecletismo, cuja banalização e homogeneização do espaço discursivo precisamente tornaria impossível a emergência do transicional. É como não ter lido o imortal retrato do bricoleur que Lévi-Strauss traçou há algumas décadas. Certamente, essa latência, essa espera, esse compasso de espera do "tudo pode servir", não se parece em nada ao imperturbável movimento através do qual, na posição do eclético, tudo é justaposto e mesclado sem mora, sem demora alguma; já que "tudo pode servir", continua-se com reticências e um "sim" e um "talvez" implícitos. O ecletismo pressupõe a renúncia a colocar condições e a colocar em condições o que se trataria de encaixar. A mínima bricolagem exige uma 
montagem, trabalho que o eclético nem sequer chega a questionar como indispensável ${ }^{4}$.

Precisamente essa necessidade de enxerto, de "ir e vir" (Winnicott) entre conceitualizações diversas, compondo assim uma estratégia multifatorial - a renúncia à facilidade narcisista ou a renúncia narcisista à facilidade de explicar tudo com uma só teoria, motivo característico da posição dogmática -, parece-nos mais necessária e justificada que nunca quando se trata do matizado panorama da aprendizagem, de suas diversas patologias e das intervenções do psicanalista neste campo, já confuso quando examinamos o termo "aprender", unidade nocional passível de ser separada em diversos planos. $O$ psicanalista não deveria evitar aproximar-se da palavra "aprender" com as mesmas precauções e a mesma pouca confiança que the inspiram ou deveriam inspirar-lhe outras palavras do vocabulário da psicologia "geral”: atenção, por exemplo, ou sensação, ou inteligência, etc. Com uma diferença: algumas delas foram dessignificadas e retrabalhadas pelo pensamento psicanalítico, e ainda assim isto não deve tranqüilizar-nos no que diz respeito a sua carga semântica originária, impregnada de mitemas e de partições metafísicas. Mas não é este o caso do verbo aprender. Tendo incidido sobre ele, a psicanálise não o expropriou, não o tomou por sua conta, como se retrocedesse diante da velha dicotomia que a destinava a ocupar-se da "afetividade", deixando para outras disciplinas talvez mais "científicas" fazê-lo com os "processos cognitivos".

Ironia, talvez: o psicanalista há muito tempo multiplica suas intervenções - tendência crescente nas estatísticas de consultório deste que escreve o presente artigo, comparando-a com seu estado há duas ou três décadas - sobre diferentes formas e diferentes níveis de "problemáticas" ou de "transtornos" de aprendizagem. O psicanalista é requisitado freqüentemente pelas escolas, que costumam pressionar famílias relutantes para a consulta, tanto no caso de meninos e meninas como de adolescentes. E não só para que o psicanalista leve a cabo um tratamento. A diretora, a professora, a psicopedagoga telefonam-lhe para trocar impressões, combinar estratégias, pedir conselhos ou assessoria concreta sobre como ajudar o aluno em questão; colocando em suas mãos, até mesmo, a responsabilidade de uma decisão sobre a criança passar de ano ou sobre a conveniência da continuidade na instituição.

O psicanalista, que tradicionalmente, segundo os cânones da rede simbólica metafísica que todo o mundo maneja, "não se ocupava” ou pouco se ocupava dos problemas “intelectuais” ou "cognitivos”, não é tão requisitado por nenhuma outra instituição como pela educacional. Raramente um neurologista ou um pediatra 
requisitam-no tanto como uma psicopedagoga ou uma professora de classe especial. Tais requisições têm "educado" o psicanalista, ao amenizar certa rigidez de seus dispositivos de atenção, forçando sua saída do enquadramento tradicional de seu trabalho e fazendo-o descobrir - a rigor, fazendo-o aprender algo sobre - as potencialidades da psicanálise para pensar diferentes circunstâncias subjetivas, emancipado de padrões técnicos já estabelecidos.

$\mathrm{E}$ isso porque suscitou intervenções eficazes; por meio da aliança do psicanalista com os profissionais da educação conseguiu-se transpor impasses difíceis, estancamentos que ameaçavam tornar-se crônicos na vida de muitas crianças e de outros tantos adolescentes. $O$ mesmo ocorreu com tratamentos psicanalíticos originados em fracassos escolares, obtendo-se melhorias mesmo naqueles casos em que fatores biológicos irreversiveis geram um atraso somente parcialmente retificável. E também não se pode concluir, prioritariamente, que a pressão desta demanda sobre o psicanalista obedeça regularmente a imperativos conformistas de adaptação, a ideais que se encarnam na forma de significantes: com freqüência apelam ao psicanalista a partir da pergunta e da inquietude pela subjetividade da criança, da preocupação por sua criatividade, tomada esta palavra no horizonte em que é pensada por Winnicott, ou seja, longe da submissão a novos critérios de rendimento quantificáveis em um boletim escolar.

Formulando isso em termos de um balanço geral, os empreendi- mentos do psicanalista em situações reconheciveis sob o apelativo "problemas de aprendizagem" - apelativo cuja múltipla indefinição incita ao questionamento -, empreendimentos que associam tratamentos propriamente ditos a trabalho em consulta, intervenções com os pais, com as equipes docentes, encaminhamentos a outros campos de intervenção (como quando um paciente requer um trabatho psicopedagógico), etc., etc., levam a uma porcentagem de resultados francamente positivos e a uma porcentagem de melhoras relativas tanto ou mais elevada que aquela que o psicanalista costuma obter nos casos de neurose habitualmente considerados como seu campo de intervenção por excelência: tomemos como exemplo a enurese, fobias de diferente magnitude, tal como as que se apresentam como transtornos do sono, comportamentos de tipo obsessivo que muito rapidamente afetam a relação da criança com seus pares, etc.

Contudo, o psicanalista não se apropria da palavra aprender e do campo semântico no qual ela se sustenta com a mesma determinação com a qual em outro momento incumbiu-se de vocábulos como "sexualidade" ou "desejo"; mantém certa inibição, uma inibição que é em si mesma um "transtorno da aprendizagem”, como se não se sentisse em sua casa e de pleno direito no que diz respeito a essa palavra e sua questão. E assim como, boa ou má, há uma teoria psicanalítica da sexualidade, das relações familiares, das patologias mais diversas (sem excluir aquelas nas quais o psicanalista colhe mais fracassos que qualquer outra coisa), não há atual- 
mente algo equivalente a uma teoria psicanalítica da aprendizagem e seus destinos.

Não porque faltem conceitos, idéias, ângulos de entrada. Depois nos referiremos a isso. Neste ponto, temos que arriscar uma interpretação.

O psicanalista formou-se em um campo discursivo que desde o princípio deu um lugar muito escasso ao "fenômeno" ou ao "afeto" da alegria. Alega as preocupações clínicas mais concretas, evidentemente para justificar que a angústia e sua família de transformações - em que o sentimento de culpa e ainda o sentimento inconsciente de culpa acabariam se juntando lado a lado com a angústia, como gêmeos não univitelinos, não idênticos - monopolizem o centro da cena.

"A little too self evident", como de costume. Apenas uma geração mais tarde, a filosofia da existência aberta por Heidegger, sem nenhuma urgência de consultório para atender, fará também da angústia seu motivo central e o caminho de acesso à verdade do humano. Existe uma longa tradição, cuja materialidade e potência histórica poderia ser demonstrada, que faz com que a alegria não seja considerada como um caminho de revelação desse tipo. "A angústia não engana”, pode-se dizer a partir de Lacan; mas, apesar de que o autor dessa frase se autodefine como "um palhaço" (e ainda que uma dimensão gozosa impregne seu estilo), a alegria não recebe dele a mesma consideração. Mais ainda, de modo característico, em seu pensamento o único momento claro e chave da aparição desta é como "júbilo" narcisista, que 
é o mesmo que dizer que fica soldada à operação constituinte subjetiva mais alienante e enganosa em relação a toda verdade possível para o sujeito (pouco antes, na obra de Melanie Klein e seus seguidores, a alegria é pouco mais que uma "defesa maníaca", se é que há uma maneira, nessa teoria, de distingui-la desta última, ou seja, uma operação encobridora, que nega uma verdade psíquica) ${ }^{5}$.

Má sorte a da alegria: na psicanálise e no pensamento ocidental em seu conjunto. Mas, restringindo-nos à primeira, encontramos, além disso, uma carência de conceitualização: basta observar como as considerações metapsicológicas de Freud sobre o princípio do prazer não desembocam na alegria, como seu complemento, o desprazer, pelo contrário, leva à questão da angústia. E, quando Freud investiga o chiste e o cômico, o excedente de prazer é referido, reativamente, a uma "economia" no que se refere à repressão. (Por aqui poderíamos chegar a vislumbrar, de uma maneira retorcida pelo reativo da concepção, um atalho para introduzir-nos na alegria e sua questão, na medida em que esse levantamento da repressão que Freud propõe leva a pensar na criação de um caminho, uma maneira de fazer caminho, desdobramento de um movimento sem interferências cujo coroamento mais evidente é a alegria como testemunho de um poder passar, vencer a resistência que obstruiria a passagem. Freud estuda isto como "facilitação" já no Projeto.)
Sua questão. Não chegou a ser, ainda, uma questão para o psicanalista. E pode ser, é a hipótese construindose, que a aprendizagem dependa e esteja regulada em última instância pela alegria, pela alegria como potencialidade e como atitude, como posição subjetiva, muito distante da alegria como "estado de ânimo" ou como afeto efetuado na consciência. Também como trabalho da alegria, poderíamos dizer: seu trabalho não é menor que o de outros como o do luto. No durch intuído, e musicalizado, por Beethoven: "através da dor".

Recapturemos a rebelião - retórica, ao menos - freudiana: "As coisas não podem ser assim!" 6 . O psicanalista precisa recuperar o que nunca teve, um pensamento da alegria e uma elucidação de seu estatuto enquanto constituinte de subjetivação, enquanto constituinte por excelência, uma das primordiais. Deveria poder capitalizar a vantagem comparativa que lhe dá o trabalhar, quando o faz, com crianças e com adolescentes, assim como seu acesso, tão aberto por Winnicott, ao bebê.

\section{O ABERTO}

Trata-se, pois, de um desvio.

Diferentemente da atitude técnica diante de um determinado problema que caracteriza o início de uma intervenção "profissional”, este, que não deve ser exatamente um profissional, o psicanalista, não entra nunca pela porta principal, não vai de frente. Assim, para esclarecer o sintoma neurótico, Freud escreve entre o final do século XIX e os primeiros anos do XX, três livros, três grandes livros, que não se 
dedicam a este, apenas tangenciando-o. É importante reter, então, que esses três livros não valem unicamente por seu conteúdo, no plano da enunciação constituem um procedimento, o procedimento de uma disciplina emergente, a psicanálise. Uma disciplina que talvez se encontre em estado emergente devido a seus transtornos de aprendizagem, que, talvez, dificultam a possibilidade de emergir plenamente.

E o que foi aberto por Winnicott incita-nos, novamente, à prática do desvio. Desvio do desvio, pois explicitamente Winnicott fala tão pouco "sobre" a alegria como qualquer outro psicanalista, mas, para começar, fala com alegria; como em Lacan, a alegria é o tom dominante de seu estilo textual. É esse o homem, recordemos (Winnicott, 1990) que quer assistir, vivo, com vida, à sua própria morte. Quer estar lá, presente, na hora de sua própria morte. Não quer que esta lhe sobrevenha por fora, dito de outra maneira, não quer ver-se excluído dela, quer estar lá quando isso, a morte, chegar.

A alegria é incompatível, nos aventuraríamos a dizer, com o sentimento da exclusão, com sua própria operação. A alegria me inclui, e não como espectador passivo. A felicidade de uma paisagem consiste em que a estou criando em conjunção com a "natureza", estou desenhando-a com todos os meus sentidos e com meu bem-estar ou, minha euforia cinestésica. É possível entender a indiferença narcisista do doente à paisagem, essa rápida indiferença que chamou a atenção de Freud: se sei que sou portador de um câncer ou se algo em meu corpo me incomoda, nada posso fazer por essa paisagem, nada de mim posso injetar nela, não posso juntar-me a ela, assim a vulnerável "objetividade” de sua beleza, deixando-me só, fica só, e retrocede à condição de um ornamento estranhamente frio, entregue a seu próprio jogo, do qual estou disjunto.

Sejamos "didáticos": é fácil chegar por esse caminho à situação do adolescente exasperando seus professores com sua indiferença desdenhosa ante o conjunto dos tesouros culturais da humanidade, que só obtém dele um "não me interessa" displicente ou elusivo. Disjunto destes, como e por que deveriam interessar-lhe? Perceber o que está lá, Winnicott ensinou-nos, não é criar o que está lá7. Por isso mesmo, o aumento de informação não é o caminho, e, mais ainda, conforme podemos observar (Corea \& Lewkowicz, 1999; Wasserman; El escalón, 1999), a proliferação desmedida de informação parece operar como um obstáculo à aprendizagem.

A situação é difícil, porque também não basta "estimular" para que se remova esse sentimento de exclusão que algumas vezes aparece para o clínico sob a forma da apatia mais extrema e outras sob a forma de uma euforia maníaca com a qual o adolescente 
nega sua falta radical de alegria e o padecimento em que esta o deixa; o nome exato deste padecimento não é dor, a falta de alegria não é dor, mas esse estado despassional e o tédio, sobretudo. O tédio, precisamente, é um grande indicador clínico do sentimento de exclusão. Experimentamos propor, então, uma formulação de Klein, partindo da alegria, para tentar esclarecer algumas das condições nas quais um processo de aprendizagem não pode ter lugar:

$$
\frac{\text { alegria }}{\text { angústia }}=\frac{\text { dor }}{\text { tédio }}
$$

Em relação ao segundo termo, inversão do primeiro, pode-se situar tudo o que corresponde às problemáticas relacionadas à inibição, que foi o primeiro conceito importante estreitamente associável às perturbações da aprendizagem que se gerou na psicanálise. (Já o exemplo a que Freud recorre para abordar o ponto, na própria abertura de "Inibição, sintoma e angústia", é mais que significativo.) Mas a função da angústia não se esgotaria em efeitos puramente negativos. Entre outros, Mario Wasserman marcou com muita agudeza como certo coeficiente do que Winnicott chamava "perseguição comum" (ou corrente, ou seja, da ordem da "psicopatologia da vida cotidiana") parece indispensável como ingrediente para motivar os atos de aprendizagem e contribuir para sua consistência.

O caso da dor tem suas próprias arestas de complexidade. Podemos encontrá-las já no caminho tortuoso da alegria, lugar que deixa vestígios, vestígios de um trabalho indispensável, também limite de referência em seu interior. A verdadeira alegria sabe que termina, o luto não sobrevive depois ${ }^{8}$. Mas, deixando isto apenas marcado, cabe dirigir a atenção à situação corrente do esforço, do esforçar-se - que à primeira vista complicaria qualquer derivação simples do aprender em relação ao brincar - e as dificuldades que em relação a este são formuladas agudamente na adolescência. Pensamos particularmente nesses casos em que o mínimo esforço ligado à posição daquele que aprende parece insuportável ao extremo, arruinando a própria possibilidade de construir a situação. Em termos freudianos, podemos dizer que alegria e dor estão desintrincadas. Se, ao contrário, estivessem intrincadas, suportariam o peso da aprendizagem como processo ${ }^{9}$. Neste contexto e como de costume, vale a pena considerar algumas expressões do discurso vulgar ("quebrou a cabeça estudando", "queima as pestanas") que fazem constar as dores e as marcas que a aprendizagem deixa no corpo, no plano pictogramático e não somente como metáfora. 
Tivemos oportunidade de dedicar-nos mais extensivamente ao tédio - junto com Alicia Fernández - em outro lugar (Rodulfo, 1995b, esp. os caps. VII e VIII) ${ }^{10}$. (O tédio, por sua vez, também nos remete a esse sentimento de exclusão que pode ser maniacamente negado, mas fecha a passagem à alegria enquanto tal.)

Um trabalho de leitura de Winnicott permite articular firmemente a alegria à criação em suas mais diversas inflexões: criação do brinquedo objeto transicional -, criação da própria espacialidade, particularmente enquanto transicional, criação - paradoxo que leva ao extremo o paradoxal do paradoxo - da própria alteridade. Passaremos ao largo de tudo isso a fim de deter-nos em um quarto motivo, que envolve a dimensão temporal, dimensão que requer uma leitura mais atenta para não passar por ausente.

Trata-se da seqüência, termo que comparece de modo regular em Winnicott, mas sem os anúncios protocolares que, em outros escritos, anunciam a chegada de um conceito, e com um desaparecimento muito rápido: mal se apresentou e já foi abrindo passagem para outros termos ou idéias... de uma seqüência cujo papel mais importante não está em formar um dos encadeamentos de um enunciado. No entanto, Winnicott localiza mais de uma no campo do trabalho psicanalítico e no curso dos processos de subjetivação; mas raramente deixa entrever a ponta de um feito: o feito da seqüência, a ação do seqüenciar como tal, a possibilidade - adquirida - de pôr em seqüência, isto é certamente mais importante. E um dos fatores pelos quais o brincar o é tem tudo a ver precisamente com o fato de que é brincando que o bebê constrói suas primeiríssimas seqüências (a própria possibilidade do desmame como trabalho e aquisição na escritura do corpo se radicará aqui). Existem condições do meio que ajudam ou entorpecem este processo de constituição de seqüência: uma rápida contraposição diferenciará - mas em uma escala cromática de matizes composta pelos mínimos intervalos audíveis aquelas situações nas quais a criança não se vê invadida e inicia com o Outro sua sequiência, na qual o sem forma da espontaneidade ganha seus primeiros delineamentos, daquelas situações nas quais diferentes intervenções potencialmente patogênicas do meio levam a criança a ter que reagir, e a partir disso a seqüencia adquire um caráter reativo e defensivo (como na criança que, diante do terror do imprevisível, fecha-se em seqüências de fixação "obsessiva"). Agora, uma das conseqüências dedutíveis de tudo isso é que a alegria emerge no curso de uma seqüência que pode ser realizada e reconhecida como própria, já que après-coup localizou um self "próprio" como efeito imaginarizado como "autor". Até certo ponto, a alegria é um índice de constituição de seqüência propositiva (não reativa), mas é algo mais, um elemento construtor que sustenta a sequiência em sua "seqüencialidade", não o "efeito" de realizá-la, como pensariam caracteristicamente Piaget e o "estruturalismo", ao desalojar "o afetivo" do plano do constitutivo. Este efeito é perceptível, mas secun- 
dário - e realimentador - do trabalho subterrâneo da alegria no próprio desejo de seqüência, desejo de seqüenciar que não é nem energia nem estrutura, precede sua configuração opositiva. (De qualquer forma, precisamos nos deter em capturar o júbilo da seqüência culminada, o júbilo evidente, ainda que também secreto quando se manifesta apenas no vigor da insistência repetitiva que Freud já destaca no jogo de atirar e (às vezes) trazer de volta do pequeno Ernst - um passo mais faltaria, na riqueza clínica dos pormenores dessa descrição, que Freud estivesse um pouco mais atento e pudesse escrever a palavra alegria: "Como seu neto gosta de atirar!" Ele? A quem dele? Quem "gosta" de atirar? A "o demoníaco" que faz de cada criança um potencial "demônio" travesso? Esquecemos aqui que o demônio tem seu lado de júbilo insolente (Don Giovanni agarrando suas "mille e tre" para atirá-las depois) tão essencial como o tema do estranho ao qual o reduziu a psicanálise clássica - extrema concentração da alegria em sea trabalho, gozo de ponta a ponta, que também faz pensar na função constitutiva da alegria no que depois será nomeado pela psicologia como capacidade de concentração, como "atenção" da criança. (Hoje a psiquiatria organicista rit(u)aliza essa enteléquia.) Deter-nos neste ponto é fundamental para considerar um dos afluentes mais indispensáveis para todo processo de aprendizagem propiciado pelos processos de brincar: a construção de seqüência, o poder colocar em seqüência, modalidade mais complexa do que há algum tempo definimos como função superfície (Rodulfo, 1990 e 1999)" ${ }^{11}$. Desde as distrações por ilusão neurótica até a dispersão em fragmentos dos transtornos narcisistas não psicóticos, sem esquecer as circularidades estereotipantes do autismo e os esburacamentos esquizofrênicos, as múltiplas formas em que o colocar em seqüência falha ou fracassa interrompendo ou minando o laço daquele que aprende com seu objeto, toda a questão do interromper que também se pensa como inibição, interromper desde o princípio ou interromper no caminho do que se está fazendo, estudando, etc., etc. A própria perspectiva de Jean Piaget permite a leitura em seu desdobramento sob o signo de uma investigação exaustiva de como a criança, a partir de uma atividade não sujeita a imposições "educativas”, erige seqüências sobre cuja "lógica” se estenderá o investigar. O tratamento psicanalítico conseguirá um primeiro resultado quando durante a sessão o paciente - no jogo, no desenho, no relato articular pela primeira vez uma seqüência com sentido (inconsciente) lá onde antes somente se encontrava uma dispersão (e a psicanálise consistiu, com algumas contradições, em "descobrir" um inconsciente que não é uma dispersão caótica). Se aquieta a turbulência, floresce a possibilidade de seqüenciar, a excitabilidade de fisio- 
nomia hipomaníaca ou ansiosa abre passagem para uma alegria cuja face consciente ou manifesta é muitas vezes a tranqüilidade, a primeira tranqüilidade, essa vigília calma alheia a qualquer "tensão de necessidade" para a qual Bettelheim foi o primeiro a chamar a atenção, não meramente como um "fato", mas em sua importância constitutiva fora dos parâmetros positivistas (que não podiam ser imaginados nada constitutivos desligados do comer ou de outras funções "biológicas", no sentido, claro, em que esse positivismo circunscreve certa concepção do biológico). Neste ponto o psicanalista - com seu próprio dispositivo de seqüências regulares e previsíveis como base, como basso continuo - trabalha como um reparador de seqüencias ou, ainda, como um iluminador, ou parteiro de um seqüenciar que não lhe pertence.

O desvio revela-se um atalho. Se há uma "rocha" no aprender e sua questão, ao menos a que encontramos nos meios psicanalíticos, se há uma dificuldade cujo aparente caráter impenetrável se desvela ao educador em suas diferentes frentes de trabalho, é a questão da criança ou do adolescente que, à margem do pouco ou muito que "renda", não consegue tomar gosto pelo aprender, sujeito no qual nenhuma aquisição ou descoberta convoca prazer algum, nem sequer quando o lado do falso self ganha seus benefícios de êxito social, de adaptação obtida. Como sempre que se tropeça com uma rocha, existirão aqueles que apelarão à fantasmagorização metapsicológica para atribuir as coisas, então, a uma pulsão epistemofilica fechada em seu impulso, como se essa "explicação" resolvesse algo por reduplicação substancialista, criando a "outra cena" do pulsional. Clinicamente, o que será decisivo é se a intervenção do psicanalista puder, na ordem da transferência, propiciar que essa alegria possa emergir em seu próprio florescimento ${ }^{12}$.

\section{QUESTÃO DE SUA QUESTÃO}

Última percepção de consultório, nos limites do presente trabalho: não assistimos ao desdobramento de outro plano dessas coisas, das coisas do aprender, para além de onde até agora estivemos nos movendo e onde psicanalista e educador têm sua margem de eficácia - teria que insistir, nada desprezível - e seus limites, um plano que pode ser pensado como de deslocamento da questão no qual precisamente a psicopatologia se detém, não podendo nos conduzir nem ajudar em nada? Tal deslocamento teria que ser pensado como histórico, se é possível apartar este termo da metafisica de um sentido ou progressão para restringir-nos à irrupção do fatual com todos seus 
acasos. Consistiria em um deslocamento tanto do horizonte como das condições do aprender, e ainda dos ideais ligados a seu dispositivo moderno no Ocidente, produzido pela entrada em cena do tele-tecno-mediático e sua injunção, seu enxerto, sua intromissão, abrindo passagem a cotoveladas na constituição da subjetividade de nossas crianças e adolescentes. $O$ recente texto de Cristina Corea e Ignacio Lewcowicz, já citado, contribui, entre outras idéias e análises críticas, com uma iluminação interessante para este assunto, que pode ser associada a essas percepções de consultório que às vezes levam tempo para poderem ser registradas: o irromper da informação, "a violência da informação" e seu pôr-dis-por a subjetividade como consumidora de informação (com a condição de despojar este termo de suas conotações oral-passivas) provocam seu impacto e entram em conflito com as vias e as instituições tradicionais da aprendizagem. No singular, cada um conciliará ou integrará isso como puder, não há por que gerar um "transtorno de aprendizagem”. Mas, no plano do aprender e sua questão, efetua um transtorno cujo desenvolvimento nos acompanha sem que possamos acreditar - e sobretudo devendo precaver-nos de acreditar - em um prognóstico que indique seu destino.

\section{REFERÊNCIAS BIBLIOGRÁFICAS}

Bleichmar, S. (2000). Clinical psicoanalitica $y$ neogénesis. Buenos Aires: Amorrortu. Corea, C \& Lewkowicz, I. (1999). Se acabó
Ja infincia. Buenos Aires: Lumen.

Derrida, J. (1990). "Glas". University of Nebraska Press.

(1999). El escalón y identificación del juego. Diarios Clinicos, 3 , e Actualidad Psicológica, 263.

Fernández, A. (1991). Lal sexualidad atrapada de la señorita maestra. Buenos Aires: Nueva Visión.

-- (2000). Poner en juego el saber. Buenos Aires: Nueva Visión.

Fernánde\%, J. C. (1999). A qué jugamos? Una reflexión sobre la capacidad de secuenciar. Actualidad Psicológica, 263.

Freud, S. (1978). Mís allí del principio del placer. T. IX. Buenos Aires: Amorrortu.

Green, A. (1997). El trabajo de lo negativo.

Lacan, J. (1978). Los cuatro conceptos fundamentales del psiconálisis. Cidade do México: Siglo XX.

--_- (1980). La troisième. Rosario: Biblioteca Freudiana de Rosario.

Maldavsky, D. (1980). El complejo de Édipo positivo: constitución y transtormaciones.

--- (1992). Teoria y clínica de los procesos tóxicos.

Pelento, M. L. (1998). Impunidad y ética. Homo Sapiens, 3.

Reinoso, D. G. (1997). El notable juego, creación e ilusión. In Rodulfo, M. \& Gonzale\%, N. (orgs.). La problemática del síntoma. Buenos Aires: Paidós.

(1998). Resistencias del psicomálisis. Buenos Aires: Eudeba.

Rodulfo, R. (1990). O brincar e o signiticante. Porto Alegre, RS: Artes Médicas.

---- (1992). Estudios clínicos. Buenos Aires: Paidós.

- - (1995a). O jogo do humor. Revistal EPSIBA, 2.

--- (1999). Descnhos fora do papel. Buenos Aires: Paidós.

Rodulfo, R. (org.) (1995b). Transtornos narcisistas nos psicólicos. Buenos Aires: Paidós.

Roitman, C. (1993). Los caminos detenidos: del desarrollo psíquico a la defu- 
sión pulsional. Buenos Aires: Nueva Visión.

Safranski, R. (1997). Un maestro de Alemania. Barcelona: Tusquets.

Stern, D. (1991). El mundo interpersonal del infante. Buenos Aires: Paidós.

Wasserman, M. Comunicação pessoal.

Winnicott, C. (1990). Prefácio a Winnicott, D. W. Exploraciones, 2 vols. (M. L. Pelento \& J. Rodríguez, superv.). Buenos Aires: Paidós.

Winnicott, D. W. (1993). Textos selecionados da pediatria a psicanálise. Cap. XXII. Rio de Janeiro, RJ: Francisco Alves.

- (1997). Los procesos de maduración en el niño y el ambiente facilitador. Buenos Aires: Paidós.

\section{NOTAS}

1 Este trabalho é dedicado à equipe assistencial da Fundação Estudos Clínicos em Psicanálise, dirigida por Marisa Rodulfo, que trabalha com a Direção de Escola Especial (Gabinete Central) da cidade de Buenos Aires desde 1993, no tratamento e recuperação de crianças com dificuldades de aprendizagem. Assistência supervisionada, gratuita e - coisa argentina - ad honores.

2 Esta idéia deve-se em seus traços gerais a uma psicopedagoga tão próxima da psicanálise - tão próxima, que está nela -, Alicia Fernández: tomar o ponto de vista da inibição e do transtorno como universal, e não só em suas delimitações patológicas, para pensar a problemática da aprendizagem em suas várias facetas. Neste sentido, "todos" temos uma relação com a apren. dizagem mediada, mas não como mediação única, pela inibição (Fernández, 1991).

3 Uma boa descrição desse exceder a técnica está em Winnicott (1993, começo). As resistências da psicanálise a si mesma foi um dos temas formulados por Jacques Derrida em sua recente conferencia (julho de 2000) nos Estados Gerais de Paris. Também com um antecedente em Resistencias (1998).

4 Estas linhas podem valer como continuação de uma reflexão sobre a posição do psicanalista empreendida no capítulo inicial de meu livro Estudios clínicos (Rodulfo, 1992). A referência "ir e vir" em Winnicott vai e vem nas mais diversas páginas de sua obra (Winnicott, 1993, Cap. IV, por exemplo).

5 Sobre este ponto, consultar a penetrante análise contida em Safranski (1997, em especial pp. 166 e ss.). A citação em inglês no início do parágrafo corresponde, claro, à Carta roubada, de Edgar Allan Poe.

${ }^{6}$ Compondo Freud (1978) a ficção do que reage perante algo que ou o levou muito longe, ou conseguiu encerrá-lo demais. Com a primazia sem limites da pulsão de morte, regulada pela verdadeira primazia: a do princípio da inércia, cuja exigência de $Q=$ zero remete toda alegria ao estatuto do secundário e do reativo. Pois a alegria não está na abolição da diferença e sua tensão. Ver também Lacan (1978 e 1980).

7 Esta diferença é tratada em diversos lugares. Para escolher um particularmente claro, ver Winnicott (1997, Cap. XVII).

8 A referência de Winnicott, no mesmo capítulo já mencionado, introduz uma cena que compõe a meada das cenas psicanalíticas em que também a aprendizagem e sua questão está tomada - teríamos que estabelecer o inventário destas cenas, desde a do mito de Freud brincando sozinho de atirar, e brincando somente de atirar, até a da "situação estabelecida" do bebê suspenso em pegar ou não a espátula (Winnicott, 1993, Cap. IV) -, em que o brincar só se dá 


\section{Artigo}

na presença de outro (Winnicott, 1993, Cap. II) até a "fabricação de superfícies" (Rodulfo, 1990). A lista continua aberta: neste caso, o da alteridade como algo com o que se tropeça, o que opōe resistência, cujo signo "físico" é a dor do tropeço, inferior, nào obstante, à dor do tropeçar. Enquanto ao luto como estrutura de antecipaçió, remetemos a Derrida (1990). Modifica e suplementa profundamente a perspectiva clásica do luto consecutivo a uma perda, em seqüência linear.

9 Sobre este e outros pontos, ver Fernández (2000). Por outro lado, as questões de tipo metapsicológico que daqui se podem depreender experimentaram um enriquecimento entrecruzado a partir de vários ângulos, renovando criativamente problemáticas e questões muito ligadas aos pressupostos e postulados da psicanálise a emergir. Uma rápida revisão teria que incluir, pelo menos, Bleichmar (2000), Green (1997), Maldavsky (1980 e 1992; o enfoque deste autor há muitos anos se distancia bastante dessa "divisão do trabalho" que vetaria ao psicanalista intervir no âmbito do “cognitivo”), Roitman (1993), Stern (1991), etc., etc. Em outra direção, a que aponta ao transgeracional, é importante citar a linha de investigação aberta por Marilú Pelento sobre o luto (Pelento, 1998; Reinoso, 1997).

10 O Cap. XIII, de Marisa Rodulfo, traça condiçōes "de estrutura" ligadas às condições de possibilidade do tédio. Esta problemática teve um papel decisivo na delimitação proposta no livro, a partir de seu próprio título, do transtorno especificado (Rodulfo, 1995b).

11 Sobre a invenção da seqüência no brincar e o brincar propriamente dito, ver também Fernández (1999).

12 Para um rastreio da questão da alegria na psicanálise, que equivale a falar sobre sua relativa ausência no discurso psicanalítico, posso referir-me a Rodulfo (1995a), cuja geneologia, claro, conduz a "O humor", de Freud, esse breve quadro tão pleno de sugestões.

Recebido em abril/2001. 